\title{
Estimated Artificial Neural Network Modeling of Maximal Oxygen Uptake Based on Multistage 10-m Shuttle Run Test in Healthy Adults
}

\author{
Hun-Young Park ${ }^{1,2} \mathbb{D}^{\mathbb{D}}$, Hoeryoung Jung ${ }^{3} \mathbb{D}$, Seunghun Lee ${ }^{3}$, Jeong-Weon Kim ${ }^{4}$, Hong-Lae Cho ${ }^{5}$ and \\ Sang-Seok Nam ${ }^{6, *(\mathbb{D})}$
}

\section{check for} updates

Citation: Park, H.-Y.; Jung, H.; Lee, S.; Kim, J.-W.; Cho, H.-L.; Nam, S.-S. Estimated Artificial Neural Network Modeling of Maximal Oxygen Uptake Based on Multistage 10-m Shuttle Run Test in Healthy Adults. Int. J. Environ. Res. Public Health 2021, 18 , 8510. https://doi.org/10.3390/ ijerph18168510

Academic Editors: Jung-Min Lee and Hyun Chul Jung

Received: 12 July 2021

Accepted: 11 August 2021

Published: 12 August 2021

Publisher's Note: MDPI stays neutra with regard to jurisdictional claims in published maps and institutional affiliations.

Copyright: (c) 2021 by the authors. Licensee MDPI, Basel, Switzerland. This article is an open access article distributed under the terms and conditions of the Creative Commons Attribution (CC BY) license (https:// creativecommons.org/licenses/by/ $4.0 /$ )
1 Physical Activity and Performance Institute, Konkuk University, 120 Neungdong-ro, Gwangjin-gu, Seoul 05029, Korea; parkhy1980@konkuk.ac.kr

2 Department of Sports Medicine and Science, Graduate School, Konkuk University, 120 Neungdong-ro, Gwangjin-gu, Seoul 05029, Korea

3 Department of Mechanical Engineering, Konkuk University, 120 Neungdong-ro, Gwangjin-gu, Seoul 05029, Korea; jungh180@konkuk.ac.kr (H.J.); erioer95@daum.net (S.L.)

4 Graduate School of Professional Therapy, Gachon University, 1342 Seongnam-daero, Sujeong-gu, Seongnam-si 13120, Korea; zeezone@gachon.ac.kr

5 Inc. Doctor Care Company, Startup Maru Nabi, 48 Buldang 14ro, Seobuk-gu, Cheonan-si 31169, Korea; ily2604@gmail.com

6 Taekwondo Research Institute of Kukkiwon, 32 Teheran 7-gil, Gangnam-gu, Seoul 06130, Korea

* Correspondence: playdata.n@gmail.com; Tel.: +82-2-3469-0181

Abstract: We aimed to develop an artificial neural network (ANN) model to estimate the maximal oxygen uptake $\left(\mathrm{VO}_{2} \mathrm{max}\right)$ based on a multistage $10 \mathrm{~m}$ shuttle run test (SRT) in healthy adults. For ANN-based $\mathrm{VO}_{2}$ max estimation, 118 healthy Korean adults (59 men and 59 women) in their twenties and fifties (38.3 \pm 11.8 years, men aged $37.8 \pm 12.1$ years, and women aged $38.8 \pm 11.6$ years) participated in this study; data included age, sex, blood pressure (systolic blood pressure (SBP), diastolic blood pressure (DBP)), waist circumference, hip circumference, waist-to-hip ratio (WHR), body composition (weight, height, body mass index (BMI), percent skeletal muscle, and percent body), $10 \mathrm{~m}$ SRT parameters (number of round trips and final speed), and $\mathrm{VO}_{2}$ max by graded exercise test (GXT) using a treadmill. The best estimation results $\left(R^{2}=0.8206\right.$, adjusted $R^{2}=0.7010$, root mean square error; RMSE = 3.1301) were obtained in case 3 (using age, sex, height, weight, BMI, waist circumference, hip circumference, WHR, SBP, DBP, number of round trips in $10 \mathrm{~m} \mathrm{SRT}$, and final speed in $10 \mathrm{~m}$ SRT), while the worst results $\left(R^{2}=0.7765\right.$, adjusted $R^{2}=0.7206$, RMSE $=3.494$ ) were obtained for case 1 (using age, sex, height, weight, BMI, number of round trips in $10 \mathrm{~m}$ SRT, and final speed in $10 \mathrm{~m}$ SRT). The estimation results of case 2 (using age, sex, height, weight, BMI, waist circumference, hip circumference, WHR, number of round trips in $10 \mathrm{~m} \mathrm{SRT}$, and final speed in $10 \mathrm{~m}$ SRT) were lower $\left(R^{2}=0.7909\right.$, adjusted $R^{2}=0.7072$, RMSE $\left.=3.3798\right)$ than those of case 3 and higher than those of case 1 . However, all cases showed high performance $\left(R^{2}\right)$ in the estimation results. This brief report developed an ANN-based estimation model to predict the $\mathrm{VO}_{2}$ max of healthy adults, and the model's performance was confirmed to be excellent.

Keywords: maximal oxygen uptake; artificial neural network; estimation model; 10 m shuttle run test; graded exercise test

\section{Introduction}

In the field of sports medicine, cardiorespiratory fitness (CRF) is the most important physical factor in assessing health conditions, including metabolic and cardiovascular disease $[1,2]$. CRF is a physiological indicator that reflects the ability of the circulatory and respiratory systems to deliver oxygen to skeletal muscles during exercise [3]. CRF is an indicator that reflects risk factors and disease burden throughout an individual's 
lifespan, and numerous studies have reported that high levels of CRF reduce morbidity and mortality [3-7]. Additionally, a low CRF increases the risk of obesity, diabetes, hypertension, and cardiovascular disease [8-11]. As such, CRF can be used as a risk indicator that can provides information in clinical decision making, and efforts to enhance or maintain an appropriate level of CRF via physical activity are critical [1,3,12,13].

Maximal oxygen uptake $\left(\mathrm{VO}_{2} \mathrm{max}\right)$ is the main criterion for evaluating $\mathrm{CRF}$, that is, aerobic fitness [1]. $\mathrm{VO}_{2} \max$ is generally measured by indirect calorimetry, which is a method of performing graded exercise tests using a respiratory gas analyzer, heart rate monitor, and treadmill or cycle ergometer in a laboratory [1,14]. In addition, measurement of $\mathrm{VO}_{2}$ max via indirect calorimetry requires considerable effort, time, money, and a skilled workforce [14,15]. As such, Léger and Lambert [16] developed a 20 m shuttle run test (SRT) using a regression model to conveniently estimate $\mathrm{VO}_{2} \mathrm{max}(\mathrm{r}=0.84)$. Currently, $20 \mathrm{~m}$ SRT is widely used to measure cardiovascular fitness, and prediction of $\mathrm{VO}_{2} \mathrm{max}$ using a $20 \mathrm{~m}$ SRT has been reported as a useful factor in monitoring the health and physical performance of healthy individuals $[1,17,18]$. However, the regression model developed by Léger and Lambert [16] has the disadvantage that sex is not considered in the estimated equation, the participants are mainly in their twentieth year of age, and a distance of $25 \mathrm{~m}$ (straight line $20 \mathrm{~m}$ and safety distance $5 \mathrm{~m}$ ) or more is required for measurement. Besides, $20 \mathrm{~m}$ SRT was originally developed to evaluate the aerobic fitness of athletes, the estimated $\mathrm{VO}_{2} \mathrm{max}$ at the first stage was set at $27.8 \mathrm{~mL} / \mathrm{kg} / \mathrm{min}$, a high level of exercise intensity. This field test cannot, therefore, be used to evaluate aerobic fitness below a $\mathrm{VO}_{2} \mathrm{max}$ of $27.8 \mathrm{~mL} / \mathrm{kg} / \mathrm{min}$, and it would impose an excessive, high-risk workload on middle-aged subjects [19]. In previous studies, Matsuzaka et al. [20], Andersen et al. [21], and Mikawa and Senjyu [19] conducted various studies that developed a $\mathrm{VO}_{2}$ max regression model using $15 \mathrm{~m}$ or 20 m SRT; however, efforts to overcome sex, age, and spatial limitations were insufficient. Cho et al. [22] most recently developed the $10 \mathrm{~m}$ SRT to evaluate CRF in healthy adults using the regression equation and verified its validity and utility. However, they failed to come up with a regression equation for high regression rates (men: $R^{2}=0.588$, women: $\left.\mathrm{R}^{2}=0.692\right)$.

In addition to regression models, machine learning methods, including artificial neural network (ANN), have been used as regressors to predict $\mathrm{VO}_{2}$ max with given input parameters including age, sex, and body mass index (BMI) [23-26]. The ANN-based prediction model, which consists of fully connected sequential layers, can represent not only leaner features but also non-linear features of the target system in virtue of non-linear activation function such as rectified linear unit (ReLU), hyperbolic tangent, and exponential linear unit (ELU). This is the key advantage of the ANN-based prediction model compared to the linear regression model, and it enables the ANN model to be used as a powerful tool, which dramatically changes accessibility of science, research, and practice in all domains [27,28]. Przednowek et al. [1] proposed an ANN-based $\mathrm{VO}_{2}$ max prediction model using a $20 \mathrm{~m}$ SRT and reported that the ANN model provides the most accurate predictions when compared to previous regression models. However, there has not been enough previous reports to assure ANN's prediction performance to estimate physical fitness data in the field of sports science.

Therefore, the present study proposes an ANN-based prediction model for indirect $\mathrm{VO}_{2}$ max estimation using a $10 \mathrm{~m}$ SRT, which is less spatially constrained than a $20 \mathrm{~m}$ SRT. The purpose of our study is to develop estimated ANN modeling of $\mathrm{VO}_{2}$ max based multistage $10 \mathrm{~m}$ SRT, which is easier to perform than the $20 \mathrm{~m} \mathrm{SRT}$, and to compare the performance of the ANN-based prediction model with the previous regression models.

\section{Materials and Methods}

\subsection{Participants}

This was a cross-sectional study. The participants of our study were 118 healthy Korean adults $(38.3 \pm 11.8$ years, men aged $37.8 \pm 12.1$ years $(n=59 ; 15$ twenties, 15 thirties, 15 forties, and 14 fifties) and women aged $38.8 \pm 11.6$ years $(n=59 ; 15$ twenties, 15 thirties, 
15 forties, and 14 fifties)), who were selected via random sampling and who were nonsmokers and had no history of musculoskeletal, cardiovascular, or pulmonary diseases or diabetes. All study participants were provided with a detailed explanation of the purpose and process of the present study, and consent was obtained after being fully informed about the possible side effects related to the experiment before the start of the present study. The study was reviewed and approved by the Institutional Review Board of KyungHee University (KHU IRB 2014-G01) and conducted in accordance with the Declaration of Helsinki.

The characteristics of the participants are presented in Table 1, and the Consolidated Standards of Reporting Trials flow diagram is shown in Figure 1.

Table 1. Participants' characteristics.

\begin{tabular}{|c|c|c|c|}
\hline & Both $(n=118)$ & Men $(n=59)$ & Women $(n=59)$ \\
\hline Age (yrs) & $38.29 \pm 11.82$ & $37.75 \pm 12.09$ & $38.83 \pm 11.62$ \\
\hline Height $(\mathrm{cm})$ & $166.69 \pm 8.16$ & $172.69 \pm 6.19$ & $160.69 \pm 4.77$ \\
\hline Weight (kg) & $65.36 \pm 10.72$ & $72.99 \pm 8.61$ & $57.73 \pm 6.26$ \\
\hline $\mathrm{BMI}\left(\mathrm{kg} / \mathrm{m}^{2}\right)$ & $23.41 \pm 2.54$ & $24.44 \pm 2.24$ & $22.37 \pm 2.40$ \\
\hline Percent skeletal muscle (\%) & $29.86 \pm 3.76$ & $32.89 \pm 2.42$ & $26.84 \pm 2.01$ \\
\hline Percent body fat (\%) & $24.42 \pm 5.56$ & $20.97 \pm 4.51$ & $27.87 \pm 4.22$ \\
\hline $\mathrm{SBP}(\mathrm{mmHg})$ & $121.89 \pm 9.99$ & $126.61 \pm 7.07$ & $117.17 \pm 10.30$ \\
\hline $\mathrm{DBP}(\mathrm{mmHg})$ & $79.14 \pm 10.05$ & $82.85 \pm 9.32$ & $75.44 \pm 9.43$ \\
\hline Waist circumference $(\mathrm{cm})$ & $81.32 \pm 7.66$ & $84.38 \pm 7.70$ & $78.26 \pm 6.33$ \\
\hline Hip circumference $(\mathrm{cm})$ & $96.04 \pm 5.16$ & $96.62 \pm 5.52$ & $95.47 \pm 4.75$ \\
\hline WHR & $0.85 \pm 0.05$ & $0.87 \pm 0.05$ & $0.82 \pm 0.04$ \\
\hline Numbers of round trips in $10 \mathrm{~m}$ SRT (n) & $115.61 \pm 26.19$ & $131.49 \pm 24.08$ & $99.73 \pm 17.06$ \\
\hline Final speed in $10 \mathrm{~m}$ SRT $(\mathrm{km} / \mathrm{h})$ & $10.03 \pm 0.94$ & $10.56 \pm 0.89$ & $9.50 \pm 0.64$ \\
\hline $\mathrm{VO}_{2} \max$ by GXT $(\mathrm{mL} / \mathrm{kg} / \mathrm{min})$ & $44.27 \pm 7.70$ & $49.08 \pm 6.70$ & $39.46 \pm 5.26$ \\
\hline
\end{tabular}

Note: Values are expressed as the mean \pm standard deviation. BMI, body mass index; SBP, systolic blood pressure; DBP, diastolic blood pressure; WHR, waist-to-hip ratio; SRT, shuttle run test; $\mathrm{VO}_{2} \max$, maximal oxygen uptake; GXT, graded exercise test.

\subsection{Study Design}

The design of the present study is shown in Figure 2. We recruited 150 healthy adult volunteers (75 men and 75 women) in healthy adults. Subsequently, a questionnaire test using the Physical Activities Readiness Questionnaire and You and American Heart Association/American College of Sports Medicine Health/Fitness Facility Pre-Participation Screening Questionnaire and blood pressure (BP) test were performed. Additionally, cardiovascular disease risk in volunteers was classified using the criteria suggested by the American Association of Cardiovascular and Pulmonary Rehabilitation. Thirty-two volunteers with risk factors for participation in the exercise test were excluded through the screening process, and 118 volunteers participated in this study. The selected 118 participants were first subjected to waist circumference, hip circumference, waist-to-hip ratio (WHR), and body composition test. The graded exercise test (GXT) and multistage $10 \mathrm{~m}$ SRT were performed sequentially with an interval of at least 5 days. All participants underwent GXT using a treadmill (Precor 932i, Precor, WA, USA), an automatic respiration metabolic analyzer K4B2 (Cosmed, Rome, Italy), and a heart rate monitor (S610i, Polar, Helsinki, Finland). The GXT protocol started at $3.6 \mathrm{~km} / \mathrm{h}$ and increased the speed by $1.2 \mathrm{~km} / \mathrm{h}$ every $2 \mathrm{~min}$, and the treadmill slopes were set to $0 \%$ at all stages [26]. The $10 \mathrm{~m}$ SRT was measured using an automatic respiration metabolic analyzer K4B2 (Cosmed, Rome, Italy) and heart rate monitor (S610i, Polar, Helsinki, Finland) along with nine sound 
sources composed of scale (Do, $\mathrm{Re}, \mathrm{Mi}, \mathrm{Fa}$, So, $\mathrm{La}, \mathrm{Ti}, \mathrm{Do}$ ) and buzzer sounds. The detailed protocol of the $10 \mathrm{~m}$ SRT is shown in Table 2.

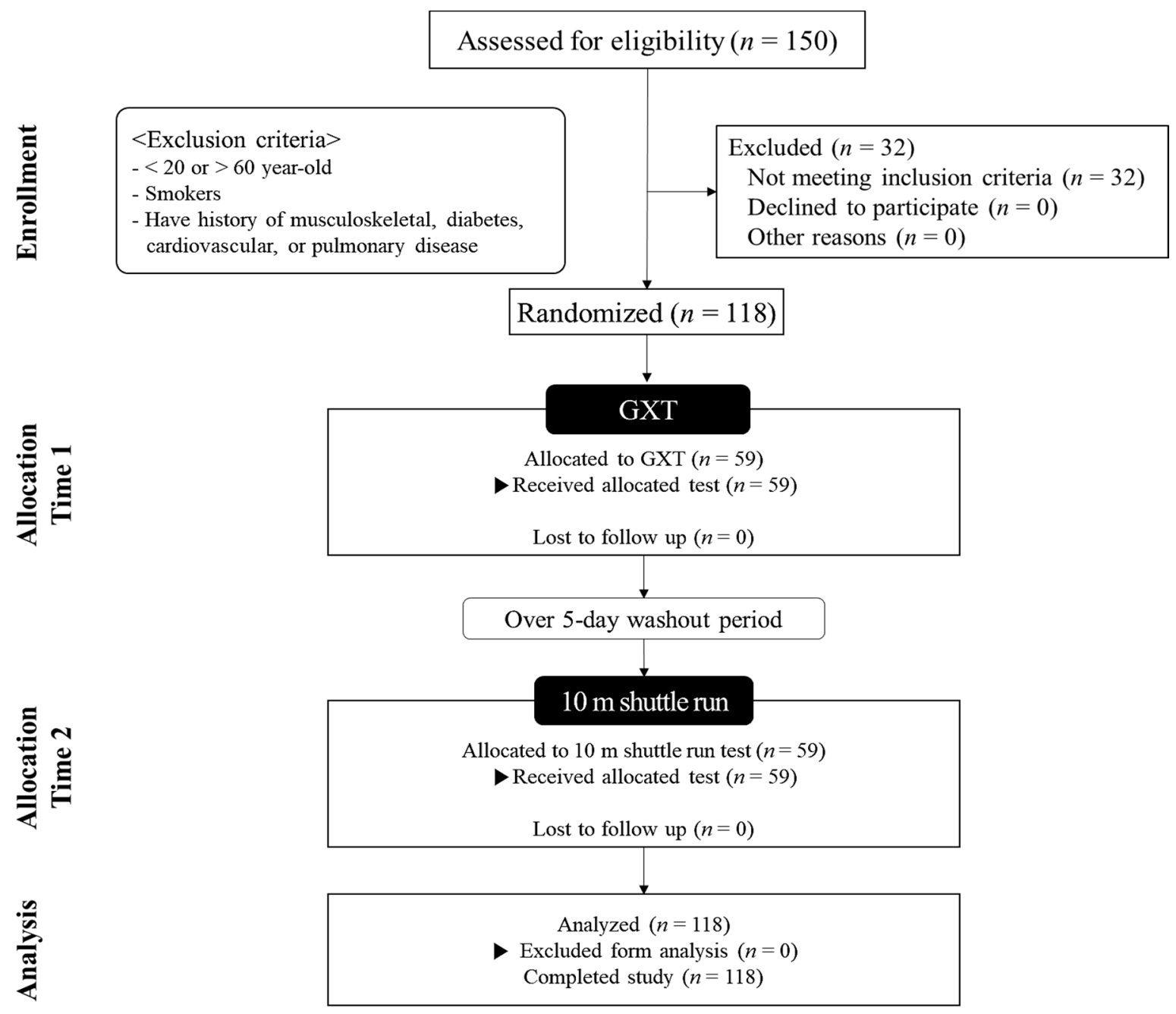

Figure 1. Consolidated Standards of Reporting Trials (CONSORT) flow diagram. GXT, graded exercise test.

After all measurements were completed, ANN modeling was performed to estimate the $\mathrm{VO}_{2}$ max measured by GXT using the easy-to-measure dependent parameters acquired via data including age; sex; $\mathrm{BP}$ (systemic blood pressure (SBP), diastolic pressure (DBP)); waist circumference; hip circumference; WHR; body composition (height, weight, BMI, percent skeletal muscle, and percent body); $10 \mathrm{~m}$ SRT parameters (number of round trips in $10 \mathrm{~m} \mathrm{SRT}$ and final speed in $10 \mathrm{~m} \mathrm{SRT)}$. For this process, the acquired data were used to train an estimated ANN model, and 30\% of the data was randomly sampled from the training dataset for the validity test.

\subsection{Blood Pressure}

After the participants sufficiently rested for $>20 \mathrm{~min}$, BP of the right brachial artery was measured twice using an autonomic BP monitor (HBP-9020, Omron, Tokyo, Japan), and the average value was used as the result value. 


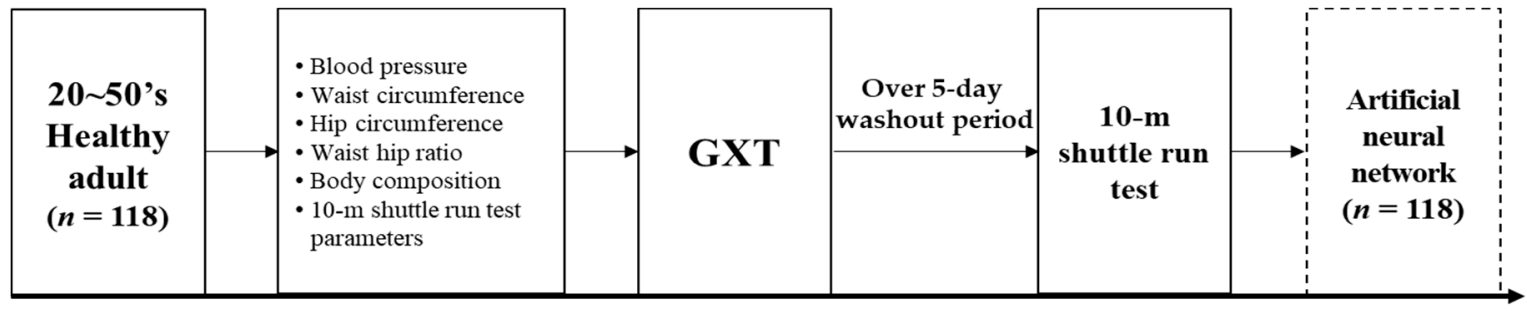

Phase 1

Phase 2

Phase 3
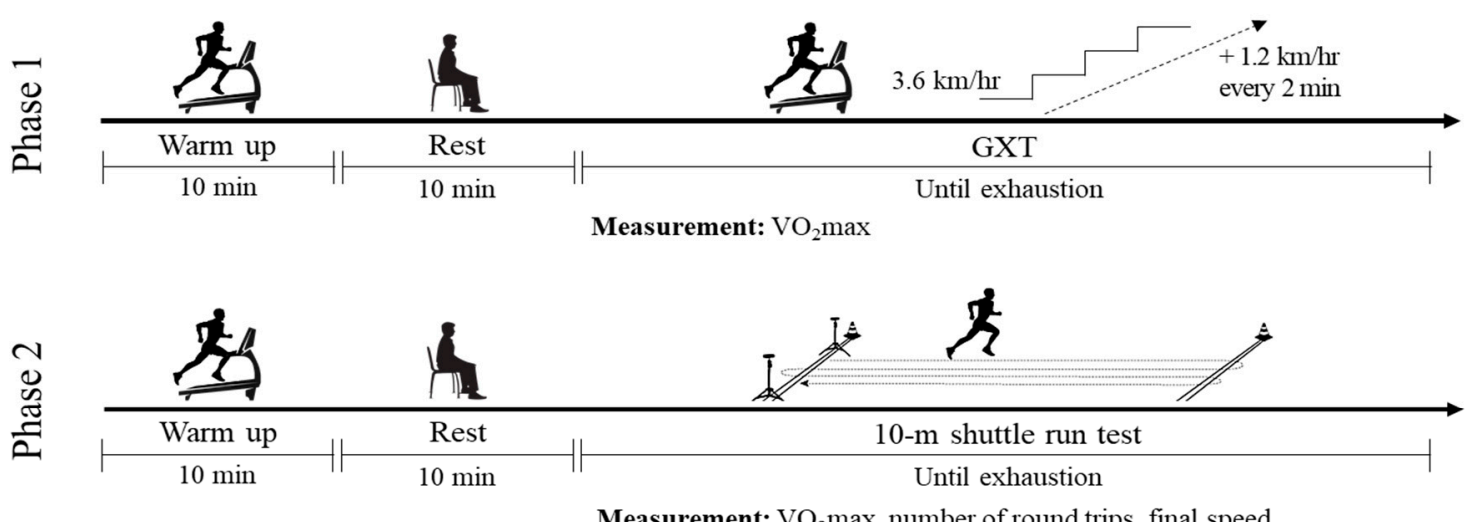

Measurement: $\mathrm{VO}_{2} \max$, number of round trips, final speed

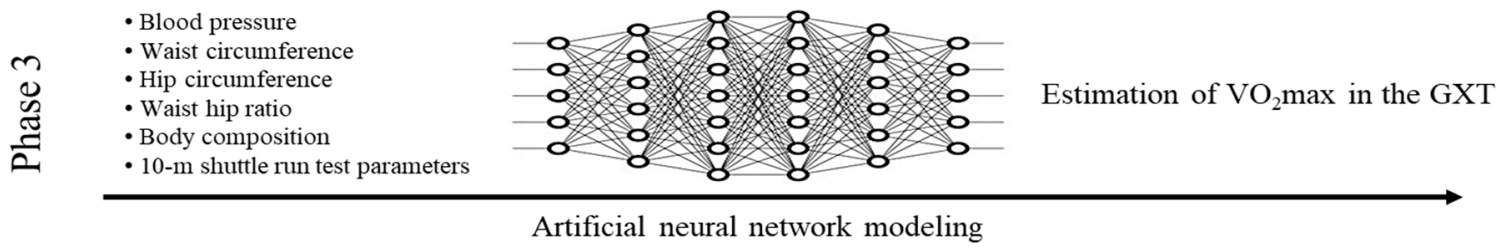

Figure 2. Study design. GXT, graded exercise test; $\mathrm{VO}_{2} \max$, maximal oxygen uptake.

Table 2. The $10 \mathrm{~m}$ shuttle run test protocol.

\begin{tabular}{|c|c|c|c|c|c|}
\hline $\begin{array}{l}\text { Start Time } \\
\text { (min) }\end{array}$ & $\begin{array}{l}\text { Finish Time } \\
\text { (min) }\end{array}$ & $\begin{array}{c}\text { Speed } \\
(\mathrm{km} / \mathrm{h})\end{array}$ & $\begin{array}{l}\text { Moving Time } \\
\text { Per } 10 \text { m (s) }\end{array}$ & $\begin{array}{c}\text { Beats } \\
\text { Per min }\end{array}$ & $\begin{array}{c}\text { Number of } \\
\text { Shuttles }\end{array}$ \\
\hline 0:00:00 & 0:01:00 & 3.6 & 10.00 & 54 & 6 \\
\hline 0:01:00 & $0: 02: 00$ & 4.8 & 7.50 & 72 & 8 \\
\hline 0:02:00 & 0:03:00 & 6.0 & 6.00 & 90 & 10 \\
\hline 0:03:00 & 0:04:00 & 6.0 & 6.00 & 90 & 10 \\
\hline 0:04:00 & 0:05:00 & 7.2 & 5.00 & 108 & 12 \\
\hline 0:05:00 & 0:06:00 & 7.2 & 5.00 & 108 & 12 \\
\hline 0:06:00 & 0:07:00 & 8.4 & 4.29 & 126 & 14 \\
\hline 0:07:00 & 0:08:00 & 8.4 & 4.29 & 126 & 14 \\
\hline 0:08:00 & 0:09:00 & 9.6 & 3.75 & 144 & 16 \\
\hline 0:09:00 & 0:10:00 & 9.6 & 3.75 & 144 & 16 \\
\hline $0: 10: 00$ & $0: 11: 00$ & 10.8 & 3.33 & 162 & 18 \\
\hline 0:11:00 & $0: 12: 00$ & 10.8 & 3.33 & 162 & 18 \\
\hline $0: 12: 00$ & 0:13:00 & 12.0 & 3.00 & 180 & 20 \\
\hline 0:13:00 & 0:14:00 & 12.0 & 3.00 & 180 & 20 \\
\hline 0:14:00 & $0: 15: 00$ & 13.2 & 2.73 & 198 & 22 \\
\hline $0: 15: 00$ & $0: 16: 00$ & 13.2 & 2.73 & 198 & 22 \\
\hline $0: 16: 00$ & $0: 17: 00$ & 14.4 & 2.50 & 216 & 24 \\
\hline 0:17:00 & 0:18:00 & 14.4 & 2.50 & 216 & 24 \\
\hline $0: 18: 00$ & 0:19:00 & 15.6 & 2.31 & 234 & 26 \\
\hline $0: 19: 00$ & $0: 20: 00$ & 15.6 & 2.31 & 234 & 26 \\
\hline $0: 20: 00$ & $0: 21: 00$ & 16.8 & 2.14 & 252 & 28 \\
\hline $0: 21: 00$ & 0:22:00 & 16.8 & 2.14 & 252 & 28 \\
\hline
\end{tabular}




\subsection{Waist Circumference, Hip Circumference, and WHR}

Waist circumference and hip circumference were measured using a tape measure (Balzer 80206F, Hoechstmass, Sulzbach, Germany). The waist circumference was measured at the level of the navel, and the hip circumference was measured at the greatest protrusion. Moreover, the WHR was calculated by dividing the waist circumference $(\mathrm{cm})$ by the hip circumference $(\mathrm{cm})$.

\subsection{Body Composition}

The body composition parameters (height, weight, BMI, percent skeletal muscle, and percent body) of all the participants were analyzed using a stadiometer (YM-1, KDS, Seoul, Korea) and bioelectrical impedance analyzer (Karada scan, Omron, Kyoto, Japan). All participants wore lightweight clothing and were asked to remove all metal items on their body.

\subsection{Graded Exercise Test}

The GXT was performed using a treadmill (Precor 932i, Precor, WA, USA), an automatic respiration metabolic analyzer K4B2 (Cosmed, Rome, Italy), and a heart rate monitor (S610i, Polar, Helsinki, Finland). The GXT protocol started at $3.6 \mathrm{~km} / \mathrm{h}$ and increased the speed by $1.2 \mathrm{~km} / \mathrm{h}$ every $2 \mathrm{~min}$, and the treadmill slopes were set to $0 \%$ at all stages [19]. Respiratory gas data (minute ventilation, oxygen uptake, carbon dioxide excretion, and respiratory exchange ratio and heart rate (HR)) were measured every $10 \mathrm{~s}$ during GXT, and blood lactate levels were analyzed using a Lactate pro2 (Arkray, Kyoto, Japan) by collecting $80 \mu \mathrm{L}$ of blood from the capillaries in the fingertips every min during GXT. When at least three of the following conditions were fulfilled while performing GXT, it was judged to have reached the stage of exhaustion, and the exercise was terminated, and $\mathrm{VO}_{2} \mathrm{max}$, the result value, was acquired: (1) when the $\mathrm{HR}$ did not increase in proportion to exercise intensity, (2) when $\mathrm{VO}_{2}$ did not increase, even when exercising intensity increased, (3) when the respiratory exchange ratio (RER) was 1.10 or higher, (4) when the Borg scale score was 17 or higher, and (5) when the predicted HRmax exceeded 90\% HRmax.

\subsection{Ten-Meter Shuttle Run Test}

The $10 \mathrm{~m}$ SRT was performed using an automatic respiration metabolic analyzer K4B2 (Cosmed, Rome, Italy) and heart rate monitor (S610i, Polar, Helsinki, Finland), and the speed was controlled by nine sound sources ( $\mathrm{Do}, \mathrm{Re}, \mathrm{Mi}, \mathrm{Fa}$, So, La, Ti, Do) and a buzzer sound. The 10-SRT adjusts the speed of by nine sound sources, providing incremental exercise load similar to the GXT. Therefore, we converted the speed of each step in the step-by-step $10 \mathrm{~m}$ SRT to beats per min and adjusted the playback speed of the sound accordingly. The $10 \mathrm{~m}$ SRT also checked the oxygen uptake and HR like the GXT, and in consideration of the characteristics of the $10 \mathrm{~m} \mathrm{SRT}$, the test was terminated when the participant could not repeatedly follow the speed of the sound source. The result value obtained via the $10 \mathrm{~m}$ SRT corresponded to $\mathrm{VO}_{2} \mathrm{max}$, the number of round trips, and the final speed.

\subsection{Statistical Analysis}

All statistical analyses were conducted using SPSS version 25.0 (IBM Corp., Armonk, NY, USA) for Windows. Data are presented as mean \pm standard deviation. The normality of the distribution of all outcome variables was verified using the Shapiro-Wilk test. A paired $t$-test was used to verify the difference between $\mathrm{VO}_{2}$ max in the GXT and $\mathrm{VO}_{2}$ max in the $10 \mathrm{~m}$ SRT. Pearson's correlation analysis was used to analyze the correlation between dependent parameters and $\mathrm{VO}_{2}$ max measured by GXT and the correlation between the measured $\mathrm{VO}_{2}$ max and the estimated $\mathrm{VO}_{2}$ max. Statistical significance was set at $p<0.05$. 


\subsection{Artificial Neural Network-Based Prediction Model}

An ANN, which is a fully connected feedforward network composed of three different types of layers, that is, the input layer, hidden layer, and output layer, was used to construct the $\mathrm{VO}_{2}$ max prediction models. The input layer consisted of 14 nodes (independent variables) and received predictors to estimate $\mathrm{VO}_{2}$ max. The input variables were age; sex; blood pressure (SBP, DBP); waist circumference; hip circumference; WHR; body composition (weight, height, BMI, percent skeletal muscle, and percent body fat); $10 \mathrm{~m}$ SRT parameters (number of round trips and final speed). These input data are standardized so that the average and standard deviation of all input data are equal to 0 and 1 , respectively, to prevent biased output to the specific input parameter. The standardized input data are passed to the hidden layers, which are composed of three layers with 21 nodes (a total of 63 nodes), and the final estimation of $\mathrm{VO}_{2}$ max by GXT is given through the single node output layer. The proposed prediction model is a multiple-input single-output type. The $10 \mathrm{~m}$ SRT data gathered from the participants were used to train the proposed ANN-based prediction model. The Elu function is used as an activation function for all the nodes in the hidden layer. The batch normalization and dropout techniques are applied in the training of the ANN model to prevent overfitting. The training was conducted with a learning rate of 0.001 via stochastic gradient descent until the number of epochs reached 1000. The proposed ANN model was implemented using the Python (3.8.5) language using Tensorflow (2.4.1) and Keras (2.4.3) packages.

\section{Results}

3.1. Estimation Accuracy of Artificial Neural Network-Based Maximal Oxygen Uptake Prediction Model

We verified the absolute value of the standardized residual as $\geq 3$ to omit the outlier data. There were no outlier data in the ANN-based $\mathrm{VO}_{2}$ max using the GXT estimation model. The correlation between the measured $\mathrm{VO}_{2} \max$ and the dependent variables (input data) is shown in Table 3.

In total, 118 sets of SRT data were used to train the ANN-based $\mathrm{VO}_{2}$ max estimation model, and 36 sets of data randomly sampled from the training datasets were used as test data to evaluate the estimation accuracy of the proposed model. Table 4 shows the estimation accuracy of the ANN-based $\mathrm{VO}_{2}$ max prediction model. The $\mathrm{VO}_{2}$ max measured by GXT was estimated using the ANN-based prediction model by varying the input data of the model. In case 1, six input data composed of age, sex, height, weight, BMI, number of round trips in $10 \mathrm{~m} \mathrm{SRT}$, and final speed in $10 \mathrm{~m}$ SRT were used to estimate the $\mathrm{VO}_{2}$ max values: the number of input data increased in cases 2 (age, sex, height, weight, BMI, waist circumference, hip circumference, WHR, number of round trips in $10 \mathrm{~m}$ SRT, and final speed in $10 \mathrm{~m}$ SRT) and 3 (age, sex, height, weight, BMI, waist circumference, hip circumference, WHR, SBP, DBP, number of round trips in $10 \mathrm{~m} \mathrm{SRT}$, and final speed in $10 \mathrm{~m}$ SRT) to investigate the effects of the inputs on the estimation accuracy. The estimation accuracy of the ANN-based $\mathrm{VO}_{2}$ max prediction model was evaluated using $\mathrm{R}^{2}$, adjusted $\mathrm{R}^{2}$, and root mean square error (RMSE).

In the estimation models of measured $\mathrm{VO}_{2}$ max by GXT, the best estimation result $\left(R^{2}=0.8206\right.$, adjusted $\left.R^{2}=0.7010, R M S E=3.1301\right)$ was obtained in case 3, while the worst result $\left(R^{2}=0.7765\right.$, adjusted $R^{2}=0.7206$, RMSE $\left.=3.494\right)$ was obtained in case 1 . Case 2 $\left(R^{2}=0.7909\right.$, adjusted $R^{2}=0.7072$, RMSE $\left.=3.3798\right)$ showed lower estimation results than case 3 and higher estimation results than case 1. However, all the cases showed high performance in the estimation results. 
Table 3. Correlation between dependent variables (input data) and measured $\mathrm{VO}_{2}$ max by GXT (output data).

\begin{tabular}{|c|c|c|c|c|}
\hline & \multicolumn{4}{|c|}{$\mathrm{VO}_{2} \max$ by GXT } \\
\hline & & Total & Men & Women \\
\hline \multirow{2}{*}{ Age (yrs) } & Correlation & $-0.339 *$ & $-0.391 *$ & -0.412 * \\
\hline & $p$-value & 0.000 & 0.002 & 0.001 \\
\hline \multirow{2}{*}{ Height $(\mathrm{cm})$} & Correlation & $0.412 *$ & -0.182 & 0.047 \\
\hline & $p$-value & 0.000 & 0.167 & 0.724 \\
\hline \multirow{2}{*}{ Weight (kg) } & Correlation & $0.215^{*}$ & $-0.440 *$ & -0.409 * \\
\hline & $p$-value & 0.019 & 0.000 & 0.001 \\
\hline \multirow{2}{*}{$\operatorname{BMI}\left(\mathrm{kg} / \mathrm{m}^{2}\right)$} & Correlation & -0.047 & -0.431 * & -0.437 * \\
\hline & $p$-value & 0.617 & 0.001 & 0.001 \\
\hline \multirow{2}{*}{ Percent skeletal muscle (\%) } & Correlation & $0.767 *$ & $0.593 *$ & $0.526^{*}$ \\
\hline & $p$-value & 0.000 & 0.000 & 0.000 \\
\hline \multirow{2}{*}{ Percent body fat $(\%)$} & Correlation & -0.783 * & $-0.697 *$ & $-0.577 *$ \\
\hline & $p$-value & 0.000 & 0.000 & 0.000 \\
\hline \multirow{2}{*}{$\mathrm{SBP}(\mathrm{mmHg})$} & Correlation & 0.194 * & -0.198 & -0.125 \\
\hline & $p$-value & 0.036 & 0.133 & 0.347 \\
\hline \multirow{2}{*}{$\mathrm{DBP}(\mathrm{mmHg})$} & Correlation & 0.066 & $-0.300 *$ & -0.145 \\
\hline & $p$-value & 0.477 & 0.021 & 0.275 \\
\hline \multirow{2}{*}{ Waist circumference $(\mathrm{cm})$} & Correlation & -0.151 & $-0.642 *$ & -0.441 * \\
\hline & $p$-value & 0.104 & 0.000 & 0.000 \\
\hline \multirow{2}{*}{ Hip circumference (cm) } & Correlation & $-0.272 *$ & $-0.457 *$ & -0.419 * \\
\hline & $p$-value & 0.003 & 0.000 & 0.001 \\
\hline \multirow{2}{*}{ WHR } & Correlation & 0.003 & $-0.561 *$ & $-0.277^{*}$ \\
\hline & $p$-value & 0.974 & 0.000 & 0.034 \\
\hline \multirow{2}{*}{ Numbers of round trips in $10 \mathrm{~m}$ SRT $(n)$} & Correlation & 0.837 * & 0.764 * & $0.688^{*}$ \\
\hline & $p$-value & 0.000 & 0.000 & 0.000 \\
\hline \multirow{2}{*}{ Final speed in $10 \mathrm{~m}$ SRT $(\mathrm{km} / \mathrm{h})$} & Correlation & 0.777 * & $0.683 *$ & 0.611 * \\
\hline & $p$-value & 0.000 & 0.000 & 0.000 \\
\hline
\end{tabular}

Note: Values are expressed as the mean \pm standard deviation. Significant correlation between measured $\mathrm{VO}_{2}$ max by GXT and dependent variables, * $p<0.05$. BMI, body mass index; SBP, systolic blood pressure; DBP, diastolic blood pressure; WHR, waist-to-hip ratio; SRT, shuttle run test; $\mathrm{VO}_{2}$ max, maximal oxygen uptake; GXT, graded exercise test.

Table 4. Estimation accuracy of artificial neural network-based maximal oxygen uptake estimation model for three cases of various input compositions.

\begin{tabular}{cccc}
\hline & \multicolumn{3}{c}{ Measured VO $_{\mathbf{2}}$ max by GXT } \\
\cline { 2 - 4 } & $\mathbf{R}^{\mathbf{2}}$ & Adjust $\mathbf{R}^{\mathbf{2}}$ & RMSE \\
\hline Case 1 ANN-based estimation & 0.7765 & 0.7206 & 3.4940 \\
\hline Case 2 ANN-based estimation & 0.7909 & 0.7072 & 3.3798 \\
\hline Case 3 ANN-based estimation & 0.8206 & 0.7010 & 3.1301 \\
\hline
\end{tabular}

Note: The inputs of case 1 consisted of age, sex, height, weight, BMI, number of round trips in the $10 \mathrm{~m}$ shuttle run test, and final speed in the $10 \mathrm{~m}$ shuttle run test. The inputs of case 2 consist of inputs of case 1, waist circumference, hip circumference, and waist-hip ratio (WHR), and the inputs of case 3 consist of inputs of case 2, SBP, and DBP. $\mathrm{VO}_{2}$ max, maximal oxygen uptake; GXT, graded exercise test; ANN, artificial neural network; RMSE, root mean square error. 


\subsection{Difference between Measured Maximal Oxygen Uptake and Artificial Neural Network-Based} Predicted Maximal Oxygen Uptake

In the present study, there was no significant difference between the measured $\mathrm{VO}_{2}$ max by GXT and estimated $\mathrm{VO}_{2}$ max in case 1 ; however, there was a significant difference between $\mathrm{VO}_{2}$ max by GXT and the estimated $\mathrm{VO}_{2}$ max by cases 2 and 3 (Table 5). The mean bias between the measured $\mathrm{VO}_{2}$ max and the estimated $\mathrm{VO}_{2}$ max in cases 1, 2, and 3 were $-0.54 \mathrm{~mL} / \mathrm{kg} / \mathrm{min},-1.32 \mathrm{~mL} / \mathrm{kg} / \mathrm{min}$, and $-0.93 \mathrm{~mL} / \mathrm{kg} / \mathrm{min}$, respectively (Table 5). The measured and estimated $\mathrm{VO}_{2} \mathrm{max}$ in all cases showed a similar average value, and their correlation coefficients also demonstrated a significant correlation (measured $\mathrm{VO}_{2}$ max and estimated $\mathrm{VO}_{2}$ max in case 1: $r=0.890, p<0.001$; measured $\mathrm{VO}_{2}$ max and estimated $\mathrm{VO}_{2}$ max in case 2: $r=0.883, p<0.001$; measured $\mathrm{VO}_{2}$ max and estimated $\mathrm{VO}_{2}$ max in case 3: $r=0.903, p<0.001$ ) (Figure 3).

Table 5. Measured and estimated $\mathrm{VO}_{2}$ max in all cases of healthy adults.

\begin{tabular}{|c|c|c|c|c|c|}
\hline & Model & Mean \pm S.D. & Bias & $t$-Value & $p$-Value \\
\hline Case1 & $\begin{array}{l}\text { Predicted treadmill } \mathrm{VO}_{2} \max (\mathrm{mL} / \mathrm{kg} / \mathrm{min}) \\
\text { Measured treadmill } \mathrm{VO}_{2} \max (\mathrm{mL} / \mathrm{kg} / \mathrm{min})\end{array}$ & $\begin{array}{l}43.73 \pm 6.62 \\
44.27 \pm 7.70\end{array}$ & -0.54 & 1.674 & 0.097 \\
\hline Case2 & $\begin{array}{l}\text { Predicted treadmill } \mathrm{VO}_{2} \max (\mathrm{mL} / \mathrm{kg} / \mathrm{min}) \\
\text { Measured treadmill } \mathrm{VO}_{2} \max (\mathrm{mL} / \mathrm{kg} / \mathrm{min})\end{array}$ & $\begin{array}{l}42.94 \pm 5.55 \\
44.27 \pm 7.70\end{array}$ & -1.32 & 3.753 & 0.000 \\
\hline Case3 & $\begin{array}{l}\text { Predicted treadmill } \mathrm{VO}_{2} \max (\mathrm{mL} / \mathrm{kg} / \mathrm{min}) \\
\text { Measured treadmill } \mathrm{VO}_{2} \max (\mathrm{mL} / \mathrm{kg} / \mathrm{min})\end{array}$ & $\begin{array}{l}43.33 \pm 6.36 \\
44.27 \pm 7.70\end{array}$ & -0.93 & 3.012 & 0.003 \\
\hline
\end{tabular}

Note: $\mathrm{VO}_{2} \max$, maximal oxygen uptake.
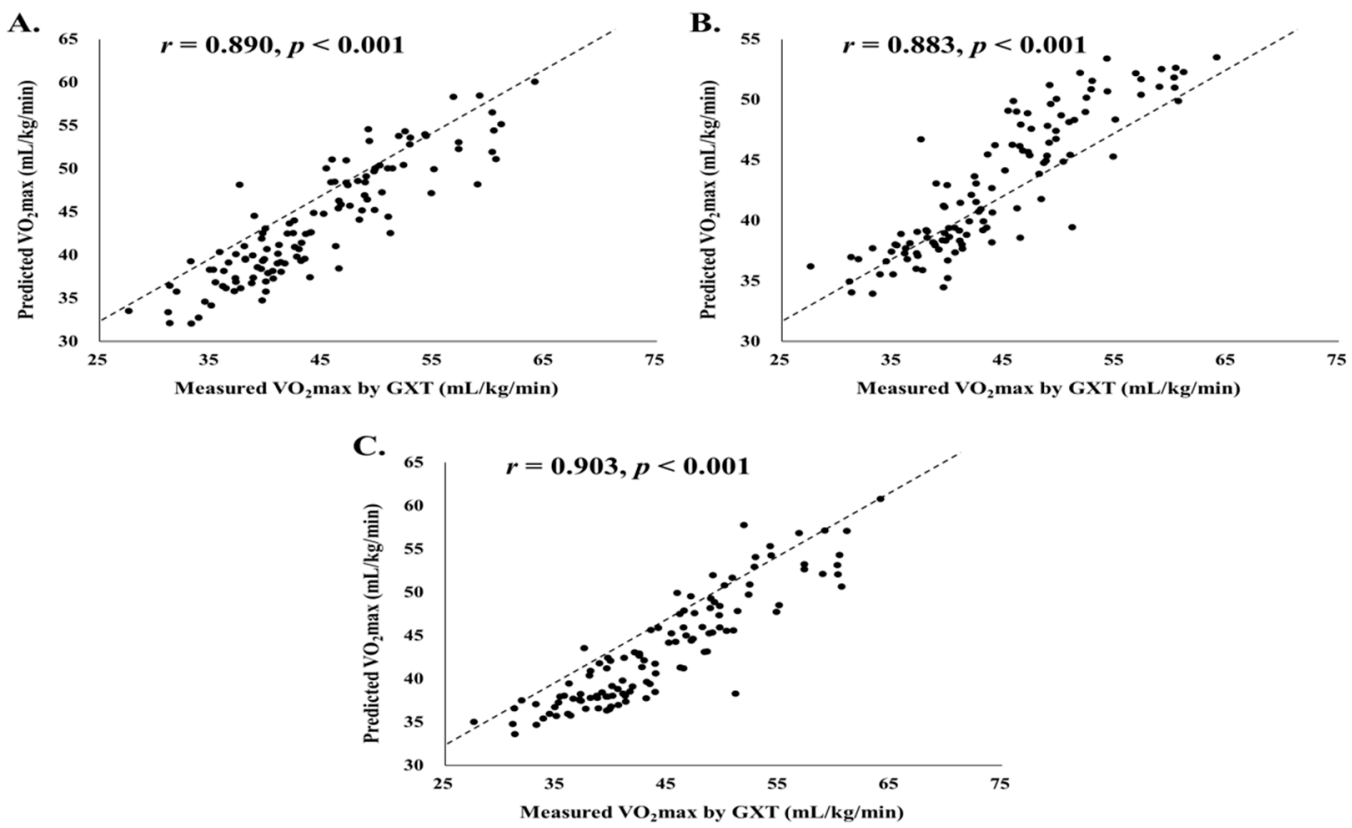

Figure 3. Scatter plot between measured $\mathrm{VO}_{2}$ max by GXT and the estimated $\mathrm{VO}_{2}$ max by case 1 , case 2 , and case 3 of healthy adults. (A). Case 1 scatter plot and correlation. (B). Case 2 scatter plot and correlation. (C). Case 3 scatter plot and correlation. GXT, graded exercise test; $\mathrm{VO}_{2} \max$, maximal oxygen uptake.

\section{Discussion}

Our brief report was conducted to develop an ANN-based estimation model for predicting the $\mathrm{VO}_{2}$ max of healthy adults using $10 \mathrm{~m}$ SRT parameters (number of round trips in $10 \mathrm{~m}$ SRT and final speed in $10 \mathrm{~m}$ SRT) and various easy-to-measure dependent variables (age, sex, height, weight, BMI, waist circumference, hip circumference, WHR, SBP, and DBP). Based on the data obtained, we developed three cases of ANN-based $\mathrm{VO}_{2}$ max estimation models (case $1: \mathrm{R}^{2}=0.7765$, adjusted $\mathrm{R}^{2}=0.7206$, RMSE $=3.494$, case 2 : 
$R^{2}=0.7909$, adjusted $R^{2}=0.7072$, RMSE $=3.3798$, case $3: R^{2}=0.8206$, adjusted $R^{2}=0.7010$, RMSE $=3.1301$ ).

$\mathrm{VO}_{2}$ max is the main criterion for evaluating CRF, that is, aerobic fitness [1], and is a strong health indicator [1-3]. Previous studies have reported that high levels of CRF reduce morbidity and mortality, and low CRF levels increase the risk of obesity, diabetes, hypertension, and cardiovascular disease [3-11]. Therefore, the easy and convenient measurement of $\mathrm{VO}_{2}$ max is critical for evaluating CRF [1,14,15]. Thus, many researchers have tried various methods to easily and conveniently estimate $\mathrm{VO}_{2} \mathrm{max}$, and a regression model for estimating $\mathrm{VO}_{2}$ max using a $20 \mathrm{~m}$ SRT has been commonly used [16-21]. In this regard, Léger and Lambert [16] first validated the $20 \mathrm{~m}$ SRT using a regression model for conveniently estimated $\mathrm{VO}_{2}$ max in 91 adults (32 women and 59 men, aged $27.3 \pm 9.2$ and $24.8 \pm 5.5$ years, respectively) and with mean $\mathrm{VO}_{2} \max (39.3 \pm 8.3$ and $51.6 \pm 7.8 \mathrm{~mL} / \mathrm{kg} / \mathrm{min}$, respectively). Consequently, they reported the following regression model: $\mathrm{VO}_{2} \max =5.857 \times$ final speed in $10 \mathrm{~m} \mathrm{SRT}-19.458, r=0.84$, and SEE $=5.4$ and concluded that a $20 \mathrm{~m}$ SRT is a valid and reliable test for the estimation of $\mathrm{VO}_{2}$ max in male and female adults. Silva et al. [29] verified two models to estimate $\mathrm{VO}_{2} \max$ in 104 Portuguese youths (54 girls and 60 boys), aged 10-18 years, using a $20 \mathrm{~m}$ SRT, and recommended the following multiple linear regression model: $\mathrm{VO}_{2}$ max $=43.313+4.567 \times$ sex $-0.560 \times \mathrm{BMI}+2.785 \times$ stage; $r=0.84$, SEE $=4.9$. Matsuzaka et al. [20] examined the validity of a $20 \mathrm{~m}$ SRT as an aerobic fitness test for young adults (56 men and 99 women aged 18-23 years) and reported the following regression model: 1. $\mathrm{VO}_{2} \max =-2.19-3.46 \times$ sex $-0.416 \times \mathrm{BMI}+5.22 \times$ maximal running speed $\left(\mathrm{R}^{2}=0.88\right.$, $\mathrm{SEE}=3.0 \mathrm{~mL} / \mathrm{kg} / \mathrm{min}), 2 . \mathrm{VO}_{2} \max =42.4-2.85 \times \mathrm{sex}-0.488 \times \mathrm{BMI}+0.247 \times$ total laps $\left(\mathrm{R}^{2}=0.88, \mathrm{SEE}=3.0 \mathrm{~mL} / \mathrm{kg} / \mathrm{min}\right)$. These previous studies confirm that estimation of $\mathrm{VO}_{2}$ max using multiple regression equations is a suitable method.

Recently, modified SRT with a reduced distance has been developed to simplify measurements and reduce spatial constraints. Takuro et al. [30] investigated the reproducibility of $15 \mathrm{~m}$ SRT in 25 healthy adults and concluded that a $15 \mathrm{~m}$ SRT provides reproducible results for the assessment of exercise capacity in healthy young participants. Mikawa and Senjyu [19] developed a modified SRT, the $15 \mathrm{~m} \mathrm{SRT,} \mathrm{to} \mathrm{assess} \mathrm{CRF} \mathrm{(} \mathrm{VO}_{2} \mathrm{max}$ ) using distance and exercise time in middle-aged adults $(n=68)$ and reported the following two regression models: $(1) \mathrm{VO}_{2} \max =14.56+0.02 \times 15$-m SRT distance $(r=0.86$, $p<0.01),(2) \mathrm{VO}_{2} \max =80.17-0.057 \times 15-\mathrm{m} \mathrm{SRT} \mathrm{time}(r=-0.51, p<0.01)$. Based on these results, they insisted that the $15 \mathrm{~m}$ SRT is valid and safe for evaluating $\mathrm{VO}_{2}$ max and is recommended as a field test for evaluating aerobic fitness in middle-aged adults.

In the present brief report, we developed a $10 \mathrm{~m}$ SRT for more convenient and practical CRF measurements in healthy adults and developed a predictive model based on ANN with various easy-to-measure dependent variables (age, sex, height, weight, BMI, waist circumference, hip circumference, WHR, SBP, DBP, number of round trips in $10 \mathrm{~m}$ SRT, and final speed in $10 \mathrm{~m} \mathrm{SRT)} \mathrm{for} \mathrm{more} \mathrm{accurate} \mathrm{and} \mathrm{reliable} \mathrm{prediction} \mathrm{of} \mathrm{VO}_{2} \mathrm{max}$. Our ANN-based modeling of $\mathrm{VO}_{2}$ max based on $10 \mathrm{~m}$ SRT in healthy adults showed better performance and accuracy (higher $\mathrm{R}^{2}$ and lower SEE) even though it is easier to measure than $15 \mathrm{~m}$ or $20 \mathrm{~m}$ estimation models using the regression equation. In particular, Cho et al. [22] developed the $10 \mathrm{~m}$ SRT in healthy adults $(n=120)$ to improve the spatial limitation by reducing the measurement to a $10 \mathrm{~m}$ distance and to resolve the bias uniform distributions of sex and age. They reported the following regression model: $1 . \mathrm{VO}_{2} \max$ $($ men $)=0.231 \times 10 \mathrm{~m}$ SRT count $-1.975 \times 10 \mathrm{~m}$ SRT final speed $-0.073 \times$ BMI -23.488 $\times \mathrm{WHR}+60.909\left(\mathrm{R}^{2}=0.588, \mathrm{SEE}=4.17 \mathrm{~mL} / \mathrm{kg} / \mathrm{min}\right), 2 . \mathrm{VO}_{2} \max ($ women $)=0.272 \times 10$ $\mathrm{m}$ SRT count $-1.530 \times 10 \mathrm{~m}$ SRT final speed $-0.649 \times \mathrm{BMI}+15.392 \times$ WHR -0.029 $\times$ age $+30.345\left(\mathrm{R}^{2}=0.692, \mathrm{SEE}=3.39 \mathrm{~mL} / \mathrm{kg} / \mathrm{min}\right)$. Compared with the study by Cho et al. [22], which developed a $\mathrm{VO}_{2}$ max estimation model using the same $10 \mathrm{~m}$ SRT based on similar participants (twenties and fifties healthy adults) and sample sizes ( $n=120)$, our ANN-based $\mathrm{VO}_{2}$ max modeling is an accurate and valid method for estimating $\mathrm{VO}_{2}$ max. Moreover, considering the high positive correlation (case 1: $r=0.890, p<0.001$; case 2: 
$r=0.883, p<0.001$; case 3: $r=0.903, p<0.001$ ) between the measured $\mathrm{VO}_{2}$ max by GXT and estimated $\mathrm{VO}_{2}$ max in all models of the three cases we developed, we can confirm that our ANN-based modeling shows high validity and reliability. Therefore, our estimated ANN-based $\mathrm{VO}_{2}$ max modeling-based multistage $10 \mathrm{~m}$ SRT can be effectively utilized to evaluate $\mathrm{CRF}$, the most important factor for estimating adult health conditions, including metabolic and cardiovascular disease.

In the present study, we presented that $10 \mathrm{~m}$ SRT with an ANN-based estimation model can be used to predict $\mathrm{VO}_{2}$ max in easy and reliable manner, but there remains a limitation that should be resolved in future research. Since the number of samples (118 samples) used to train an ANN-based estimation model is too small to represent general $\mathrm{VO}_{2}$ max characteristics, large-scale trials covering more than hundreds of subjects should be performed to secure enough training dataset and more rigorous performance validation of the estimation model. Additionally, we believe that the performance, validity, and reliability of the ANN-based estimation model between $10 \mathrm{~m}$ SRT and other simple tests estimating $\mathrm{VO}_{2}$ max should be compared.

\section{Conclusions}

In our brief report, we developed ANN-based estimation model to predict the $\mathrm{VO}_{2} \mathrm{max}$ based on multistage $10 \mathrm{~m}$ SRT in healthy adults, and the model's performance was confirmed to be excellent. Therefore, we believe that ANN-based modeling of $\mathrm{VO}_{2} \mathrm{max}$ based on multistage $10 \mathrm{~m}$ SRT is a highly scalable, effective, validated, and reliable method for predicting CRF in healthy adults.

Author Contributions: Study conception and design, H.-Y.P., H.J., and S.-S.N.; data curation, H.J., S.L., and S.-S.N.; formal analysis, H.-Y.P., H.J., and S.-S.N.; investigation, H.J., S.L., and J.-W.K.; methodology, H.-Y.P., H.J., S.L., J.-W.K., H.-L.C., and S.-S.N.; writing-original draft H.-Y.P., H.J., and S.-S.N.; writing-review and editing, H.-Y.P., H.J., S.L., J.-W.K., H.-L.C., and S.-S.N. All authors have read and agreed to the published version of the manuscript.

Funding: This study was supported by the Samsung Advanced Institute of Technology.

Institutional Review Board Statement: This study was approved by the Institutional Review Board of KyungHee University (KHU IRB 2014-G01) in Korea and was conducted as per the Declaration of Helsinki.

Informed Consent Statement: Informed consent was obtained from all participants involved in the study.

Data Availability Statement: The data presented in this study are available on request from the corresponding author.

Conflicts of Interest: The authors declare no conflict of interest.

\section{References}

1. Przednowek, K.; Barabasz, Z.; Zadarko-Domaradzka, M.; Przednowek, K.H.; Nizioł-Babiarz, E.; Huzarski, M.; Sibiga, K.; Dziadek, B.; Zadarko, E. Predictive Modeling of $\mathrm{VO}_{2}$ max Based on $20 \mathrm{~m}$ Shuttle Run Test for Young Healthy People. Appl. Sci. 2018, 8, 2213. [CrossRef]

2. Ross, R.; Blair, S.N.; Arena, R.; Church, T.S.; Després, J.-P.; Franklin, B.A.; Haskell, W.L.; Kaminsky, L.A.; Levine, B.D.; Lavie, C.J. Importance of assessing cardiorespiratory fitness in clinical practice: A case for fitness as a clinical vital sign: A scientific statement from the American Heart Association. Circulation 2016, 134, e653-e699. [CrossRef]

3. Chu, D.J.; Al Rifai, M.; Virani, S.S.; Brawner, C.A.; Nasir, K.; Al-Mallah, M.H. The relationship between cardiorespiratory fitness, cardiovascular risk factors and atherosclerosis. Atherosclerosis 2020, 304, 44-52. [CrossRef] [PubMed]

4. Barlow, C.E.; LaMonte, M.J.; Fitzgerald, S.J.; Kampert, J.B.; Perrin, J.L.; Blair, S.N. Cardiorespiratory fitness is an independent predictor of hypertension incidence among initially normotensive healthy women. Am. J. Epidemiol. 2006, 163, 142-150. [CrossRef] [PubMed]

5. Joyner, M.J.; Green, D.J. Exercise protects the cardiovascular system: Effects beyond traditional risk factors. J. Physiol. 2009, 587, 5551-5558. [CrossRef]

6. Walsh, N.P.; Gleeson, M.; Shephard, R.J.; Gleeson, M.; Woods, J.A.; Bishop, N.C.; Fleshner, M.; Green, C.; Pedersen, B.K.; Hoffman-Goetz, L.; et al. Position statement. Part one: Immune function and exercise. Exerc. Immunol. Rev. 2011, 17, 6-63. 
7. Wilson, M.G.; Ellison, G.M.; Cable, N.T. Basic science behind the cardiovascular benefits of exercise. Postgrad. Med. J. 2015, 91, 704-711. [CrossRef]

8. Kodama, S.; Saito, K.; Tanaka, S.; Maki, M.; Yachi, Y.; Asumi, M.; Sugawara, A.; Totsuka, K.; Shimano, H.; Ohashi, Y.; et al. Cardiorespiratory fitness as a quantitative predictor of all-cause mortality and cardiovascular events in healthy men and women: A meta-analysis. JAMA 2009, 301, 2024-2035. [CrossRef] [PubMed]

9. Gray, B.J.; Stephens, J.W.; Williams, S.P.; Davies, C.A.; Turner, D.; Bracken, R.M. Cardiorespiratory fitness is a stronger indicator of cardiometabolic risk factors and risk prediction than self-reported physical activity levels. Diabetes Vasc. Dis. Res. 2015, 12, 428-435. [CrossRef]

10. Ling, J.C.; Mohamed, M.N.; Jalaludin, M.Y.; Rampal, S.; Zaharan, N.L.; Mohamed, Z. Determinants of High Fasting Insulin and Insulin Resistance among Overweight/Obese Adolescents. Sci. Rep. 2016, 6, 36270. [CrossRef] [PubMed]

11. Silva, D.R.; Werneck, A.O.; Collings, P.J.; Ohara, D.; Fernandes, R.A.; Barbosa, D.S.; Ronque, E.R.V.; Sardinha, L.B.; Cyrino, E.S. Cardiorespiratory fitness effect may be under-estimated in 'fat but fit' hypothesis studies. Ann. Hum. Biol. 2017, 44, 237-242. [CrossRef]

12. Cao, Z.B.; Miyatake, N.; Higuchi, M.; Miyachi, M.; Ishikawa-Takata, K.; Tabata, I. Predicting $\mathrm{VO}_{2}$ max with an objectively measured physical activity in Japanese women. Med. Sci. Sports Exerc. 2010, 42, 179-186. [CrossRef]

13. Strasser, B.; Burtscher, M. Survival of the fittest: $\mathrm{VO}_{2} \mathrm{max}$, a key predictor of longevity? Front. Biosci. 2018, 23, 1505-1516. [CrossRef]

14. Wier, L.T.; Jackson, A.S.; Ayers, G.W.; Arenare, B. Nonexercise models for estimating $\mathrm{VO}_{2}$ max with waist girth, percent fat, or BMI. Med. Sci. Sports Exerc. 2006, 38, 555-561. [CrossRef]

15. Cao, Z.B.; Miyatake, N.; Higuchi, M.; Ishikawa-Takata, K.; Miyachi, M.; Tabata, I. Prediction of $\mathrm{VO}_{2}$ max with daily step counts for Japanese adult women. Eur. J. Appl. Physiol. 2009, 105, 289-296. [CrossRef]

16. Léger, L.A.; Lambert, J. A maximal multistage 20-m shuttle run test to predict $\mathrm{VO}_{2}$ max. Eur. J. Appl. Physiol. Occup. Physiol. 1982, 49,1-12. [CrossRef]

17. Mahar, M.T.; Guerieri, A.M.; Hanna, M.S.; Kemble, C.D. Estimation of aerobic fitness from 20-m multistage shuttle run test performance. Am. J. Prev. Med. 2011, 41, S117-S123. [CrossRef] [PubMed]

18. Paradisis, G.P.; Zacharogiannis, E.; Mandila, D.; Smirtiotou, A.; Argeitaki, P.; Cooke, C.B. Multi-Stage 20-m Shuttle Run Fitness Test, Maximal Oxygen Uptake and Velocity at Maximal Oxygen Uptake. J. Hum. Kinet. 2014, 41, 81-87. [CrossRef] [PubMed]

19. Mikawa, K.; Senjyu, H. Development of a field test for evaluating aerobic fitness in middle-aged adults: Validity of a 15-m incremental shuttle walk and run test. J. Sports Sci. Med. 2011, 10, 712-717. [PubMed]

20. Matsuzaka, A.; Takahashi, Y.; Yamazoe, M.; Kumakura, N.; Ikeda, A.; Wilk, B.; Bar-Or, O. Validity of the multistage 20-m shuttle-run test for Japanese children, adolescents, and adults. Pediatr. Exerc. Sci. 2004, 16, 113-125. [CrossRef]

21. Andersen, L.B.; Andersen, T.E.; Andersen, E.; Anderssen, S.A. An intermittent running test to estimate maximal oxygen uptake: The Andersen test. J. Sports Med. Phys. Fitness 2008, 48, 434-437. [PubMed]

22. Cho, H.-L.; Park, H.-Y.; Nam, S.-S. Development of multistage 10-m shuttle run test for $\mathrm{VO}_{2}$ max estimation in healthy adults. J. Men's Health 2021, 17, 1-8. [CrossRef]

23. Akay, M.; Özsert, G.; George, J. Prediction of maximal oxygen uptake using support vector machines from submaximal data. DEÜ Eng. Fac. Eng. Sci. J. 2014, 16, 42-48.

24. Aktürk, E.; Akay, M. Prediction of maximal oxygen uptake using multilayer perceptron combined with feature selection. In Proceedings of the 7th Engineering and Technology Symposium, Ankara, Turkey, 15-16 May 2014; pp. 3-6.

25. Abut, F.; Akay, M.F.; George, J. Developing new $\mathrm{VO}_{2}$ max prediction models from maximal, submaximal and questionnaire variables using support vector machines combined with feature selection. Comput. Biol. Med. 2016, 79, 182-192. [CrossRef] [PubMed]

26. Ham, J.H.; Park, H.Y.; Kim, Y.H.; Bae, S.K.; Ko, B.H.; Nam, S.S. Development of an anaerobic threshold (HRLT, HRVT) estimation equation using the heart rate threshold (HRT) during the treadmill incremental exercise test. J. Exerc. Nutr. Biochem. 2017, 21, 43-49. [CrossRef] [PubMed]

27. Sark, S.; Elshawi, R.; Ahmed, A.; Qureshi, W.T.; Brawner, C.; Keteyian, S.; Blaha, M.J.; Al-Mallah, M.H. Using machine learning on cardiorespiratory fitness data for predicting hypertension: The Henry Ford ExercIse Testing (FIT) Project. PLoS ONE 2018, 13, e0195344. [CrossRef]

28. Sakr, S.; Elshawi, R.; Ahmed, A.M.; Qureshi, W.T.; Brawner, C.A.; Keteyian, S.J.; Blaha, M.J.; Al-Mallah, M.H. Comparison of machine learning techniques to predict all-cause mortality using fitness data: The Henry ford exercIse testing (FIT) project. BMC Med. Inform. Decis. Mak. 2017, 17, 174. [CrossRef]

29. Silva, G.; Oliveira, N.L.; Aires, L.; Mota, J.; Oliveira, J.; Ribeiro, J.C. Calculation and validation of models for estimating $\mathrm{VO}_{2} \mathrm{max}$ from the 20-m shuttle run test in children and adolescents. Arch. Exerc. Health Dis. 2012, 3, 145-152. [CrossRef]

30. Takuro, K.; Kohei, S.; Kotarō, M.; Yoshiyasu, Y. The Reproducibility of the 15-m Shuttle Run Test, a Modified 20-m Shuttle Run Test, for the Assessment of Exercise Capacity. Rigakuryoho Kagaku 2015, 30, 81-84. [CrossRef] 